Vasilyev Peter Petrovich, doctor of economic sciences, professor of Cathedra of Economic Theory and Entrepreneurship, South-Russia Institute of Management - branch of Russian Presidential Academy of National Economy and Public Administration (70/54 Pushkinskaya St., Rostov-on-Don, 344002, Russian Federation).

E-mail: ectheory@uriu.ranepa.ru

Kharchenko Lana Ivanovna, Candidate of economic sciences, Associate Professor of Cathedra of Economic Theory and Entrepreneurship, South-Russia Institute of Management - branch of Russian Presidential Academy of National Economy and Public Administration (70/54, Pushkinskaya St., Rostov-on-Don, 344002, Russian Federation).E-mail: ectheory@uriu.ranepa.ru

\title{
SCIENTIFIC AND TECHNOLOGICAL BREAKTHROUGH AS AN IMPERATIVE OF MODERNIZATION OF THE COUNTRY'S LABOR POTENTIAL
}

Abstract

The work is devoted to the analysis of various aspects of interrelated socio-economic problems of the implementation of modern labor potential of Russia in the conditions of the need for technological breakthrough, as well as the study of methodological issues of economic development and decisions of the country's leadership aimed at achieving goals.

Keywords: labor potential, technological break, education, innovative development, labor productivity, world globalization, economic sphere, economic strategy, economic growth.

\section{References}

1. Mau V.A. Nacional'nye celi i model' ekonomicheskogo rosta: novoe v social'no-ekonomicheskoj politike Rossii v 2018-2019 gg. // Voprosy ekonomiki. 2019. № 3. P. 5 - 28.

2. Senchenya G.I. Effektivnoe ispol'zovanie intellektual'noj sobstvennost'yu // Voprosy ekonomiki. 2019 . № 3. S. $119-141$.

3. Fagerberg J., Srholec M. (2008) National innovation systems, capabilities and economic development. Research Policy, Vol. 37, №9, pp. 1417-1435.

4. Levin A.Y., Massini S., Peeters C. (2009). Why are companies offshoring innovation? The emerging global race for talent. Journal of International Business Studies, Vol. 40, №6, pp. 901-925.

5. Ignatova T.V., Vasil'ev P.P. Povyshenie znachimosti teorii chelovecheskogo kapitala dlya upravleniya rossijskoj ekonomiki. // Journal of Economic Regulation (Voprosy regulirovaniya ekonomiki). 2013. № 2. T. 4. P. 49 - 55.

6. Furman J.L., Porter M.E., Stern S. (2002). The determinants of national innovative capacity. Research Policy, Vol. 31, № 6, pp. 899-933.

7. Zvyagincev P. Upravlenie gosudarstvennoj sobstvennost'yu kak imperativ innovacionnogo razvitiya // Ekonomist. 2019. № 3. P. 54 - 60 .

8. Kurbanov T. Rossiya na puti proryva v novyj tekhnologicheskij uklad: ekonomicheskie i finansovye aspekty // Ekonomist. 2019. № 3. P. 3 - 13.

\section{ПЕРСПЕКТИВЫ РАЗВИТИЯ ИНФОРМАЦИОННОГО ОБЩЕСТВА В РОССИИ}

$\begin{array}{ll}\text { Eршова } & \text { кандидат экономических наук, доцент, зав. кафедрой экономики, } \\ \text { Наталья } & \text { Российский государственный университет правосудия (117418, Россия, } \\ \text { Анатольевна } & \text { г. Москва, ул. Новочеремушкинская, 69). E-mail: nataly_ershova@mail.ru } \\ \text { Александрова } & \text { кандидат экономических наук, доцент кафедры экономики, } \\ \text { Маргарита } & \text { Российский государственный университет правосудия (117418, Россия, } \\ \text { Валерьевна } & \text { г. Москва, ул. Новочеремушкинская, 69). E-mail: 4664290@mail.ru }\end{array}$

\section{Аннотация}

Ключевой целью статьи является рассмотрение теоретических положений по зарождению и развитию новой эпохи - эпохи цифровой экономики. При переходе к шестому технологическому укладу цифровые технологии постоянно изменяют повседневную жизнь каждого субъекта экономических отношений, а также влияют на производственные процессы, структуру экономики страны в целом, образование и медицину, культурно-просветительскую сферу, что приводит к необходимости предъявлять новые требования к информационным системам.

Ключевые слова: цифровая экономика, информационное общество, технологические платформы, информационная среда, информационное пространство, общество знаний, информированность граждан, информационная инфраструктура, конкурентоспособные производства.

Современная государственная политика России направлена на развитие общества знаний, повышение благосостояния и качества жизни населения за счет использования современных цифровых технологий, позволяющих не только повысить степень информированности граждан о происходящих в стране социально-экономических процессов, но и уровень их цифровой грамотности.

В настоящее время одной из главных тенденций развития современного мира является процесс глобализации, оказывающий влияние практически на все сферы жизни, в том числе и на 
экономику. Глобализация экономики характеризуется усилением на международном уровне тенденций, связанных с повышением влияния международных организаций, транснациональных корпораций, обострением конкурентной борьбы [1].

Для реализации этих процессов в 2017 году в целях реализации Стратегии развития информационного общества в Российской Федерации на 2017 - 2030годы, утвержденной Указом Президента Российской Федерации от 9мая 2017г. N 203 «0 Стратегии развития информационного общества в Российской Федерации на 2017 - 2030годы» распоряжением Правительства Российской Федерации N 1632-рот 28 июля 2017 г. была утверждена государственная Программа «Цифровая экономика Российской Федерации».

В Стратегии развития информационного общества сформулировано определение цифровой экономики, которая рассматривается как хозяйственная деятельность, ключевым фактором производства в которой являются данные в цифровой форме, способствующие формированию информационного пространства с учетом потребностей граждан и общества в получении качественных и достоверных сведений, развитию информационной инфраструктуры Российской Федерации, созданию и применению российских информационно-телекоммуникационных технологий, а также формированию новой технологической основы для социальной и экономической сферы ${ }^{1}$.

Основной целью Программы «Цифровая экономика Российской Федерации» является создание особой экономической среды институционального и инфраструктурного характера, выраженной в цифровой форме, обеспечивающей максимально возможное взаимодействие между различными экономическими агентами для снижения ограничений по созданию и развитию конкурентоспособных на мировом рынке высокотехнологических производств в различных отраслях экономики.

Как видно из табл., общий объем финансирования на реализацию данной Программы из средств федерального бюджета составляет более 2612 млрд. руб. ${ }^{2}$

Таблица

\section{Объем бюджетных ассигнований на реализацию Программы «Информационное общество»} за счет средств федерального бюджета

\begin{tabular}{|c|c|}
\hline Период & Объем финансирования, млрд. руб. \\
\hline 2011 год & 113,4 \\
\hline 2012 год & 145,9 \\
\hline 2013 год & 130,6 \\
\hline 2014 год & 116,2 \\
\hline 2015 год & 115,2 \\
\hline 2016 год & 122,8 \\
\hline 2017 год & 113,8 \\
\hline 2018 год & 131,8 \\
\hline 2019 год & 216,9 \\
\hline 2020 год & 229,2 \\
\hline 2021 год & 274,3 \\
\hline 2022 год & 330,2 \\
\hline 2023 год & 304,9 \\
\hline 2024 год & 267,3 \\
\hline Итого & 2612,5 \\
\hline
\end{tabular}

Источник: Государственная программа «Информационное общество» [Электронный ресурс]- Режим доступа: https://digital.gov.ru/ru

Каждый руководитель компании понимает, что важным стратегическим ресурсом, определяющим развитие организации в современных условиях хозяйствования, являются не только финансы, но и время. Для того, чтобы сократить его пустую трату, необходимо идти в ногу с развитием информационных технологий, позволяющих автоматизировать и упростить какие-либо рутинные процессы. Одним из результатов развития информационных технологий стала система электронного документооборота.

Необходимость внедрения системы в деятельность компании очевидна: в настоящее время каждая сделка должна быть документально подтверждена. И не только по причине недоверия к своему контрагенту, но и потому что так диктует законодатель. В связи с тем, что ежедневно

\footnotetext{
${ }_{1}^{1}$ Клерк [Электронный ресурс] - Режим доступа: https://www.klerk.ru

2 Государственная программа «Информационное общество» [Электронный ресурс]- Режим доступа:

https://digital.gov.ru/ru
} 
на предприятии происходит большое количество управленческих процессов, а для обеспечения его производственной деятельности необходимо множество ресурсов, получаемых извне, в организации формируется массивный документооборот, функционирующий как внутри организации, так и за ее пределами - с иными предприятиями - контрагентами.

Для того, чтобы принятые руководителем решения, выполнялись сотрудниками организации оперативно, а взаимодействие с иным предприятиями в рамках какой-либо сделки происходило с наименьшими затратами при условии получения большей выгоды, необходимо сокращать время на создание и обработку документа, а также постоянно контролировать его движение.

Благодаря системе электронного документооборота увеличивается производительность труда сотрудников компании: сокращается время на создание и распечатку документа, его перемещение от сотрудника к сотруднику, исчезают проблемы, возникающие в случае потери или утраты документа. Ускоряя и упрощая вышеперечисленные процессы, сотрудники уделяют больше внимания другим обязанностям, возложенным руководителем.

Быстрое взаимодействие с иными хозяйствующими субъектами ускоряет процесс заключения сделки, а в результате этого и получение желаемых материальных благ. Кроме того, исключается факт несоблюдения оговоренных в контракте сроков по причине формальностей. Это, в свою очередь, позволяет избежать незапланированные внереализационные расходы: пени и неустойки.

Кроме того, процесс информатизации затронул не только коммерческий сегмент, но и государство в лице его органов и внебюджетных фондов, например Федеральную налоговую службу и Пенсионный Фонд России. Теперь, обмен отчетными документами с такими субъектами в некоторых ситуациях возможен только в электронном виде, а в случае несоблюдения законодательно установленного формата документов, они считаются неподанными. Таким образом, организация нарушает возложенные на нее государством обязанности, что также влечет наложение штрафов, начисление пеней и применение санкций, которые влекут не только финансовые потери, но и мешают дальнейшей деятельности предприятия (например, приостановление операций на счетах в банке), что также отрицательно сказывается на его финансовых результатах.

При использовании систем электронного документооборота передача информации в цифровом виде выполняется за несколько минут, не говоря уже о том, что существенно сокращаются и финансовые затраты. В настоящее время большинство предприятий уже автоматизировали внутренние бизнес-процессы посредством частичного или полного внедрения и использования информационных и учетных систем. Однако необходимо понимать, что деятельность компании не ограничена только внутренними процессами, так как параллельно идет и внешнее взаимодействие с различными контрагентами.

Современные информационные и коммуникационные технологии существенно меняют все общественные отношения, в связи с чем отмечается, что в настоящее время происходит становление нового, информационного общества, которое носит название «цифровой экономики». Несмотря на отчасти схожие свойства с традиционными хозяйственными отношениями, она во многом отличается от них, что делает ее актуальной с точки зрения интереса научного сообеества [2].

Внедрение в экономическую жизнь общества цифровой экономики является действенным рычагом его эффективного развития, позволяющим расширять горизонты возможностей как внутри страны, так и в мировом сообществе.

В структуре цифровой экономики можно выделить три основных взаимосвязанных составляющих, определяющих уровень развития общества: сферы деятельности, в которых осуществляется взаимодействие поставщиков и потребителей; инновационные технологические платформы, формирующие условия для динамичного развития различных сфер деятельности; институциональная и инфраструктурная среда, обеспечивающая условия для развития технологических платформ, а также эффективное взаимодействие между субъектами рыночных отношений.

Формирование и развитие нового информационного общества в стране должно быть основано на взаимодействии таких ключевых элементах как государство, корпорации, малый бизнес и наука. Только в таких условиях возможно максимально быстро создать современные высокотехнологичные инновационные энерго- и ресурсо-эффективные предприятия, которые способны развивать «сквозные» технологии и управлять цифровыми платформами.

Малое предпринимательство играет важнейшую роль в инновационном и социальноэкономическом развитии региона, сглаживая кризисные явления в экономике, как отдельного региона, так и страны в целом. В то же время в современных условиях глобализации малым предприятиям и организациям для выживания необходима поддержка государства.

Для получения поддержки предпринимателю необходимо в короткий двадцатидневный срок собрать более десяти видов документов, что в значительной степени усложняет процесс получения 
субсидий малым бизнесом. Решение этой проблемы требует организации эффективной системы информационной поддержки малого бизнеса, при помощи которой каждый предприниматель мог бы получить всю необходимую информацию, полезные советы и в кратчайший срок подать заявление на получение субсидии [3]. Наряду с этим требуются новые кадры, способные эффективно работать в информационном обществе.

Информационное общество - это индустриальное общество, новая историческая фаза развития цивилизации, в которой главными производствами являются информация и ее высшая форма знания [4].

Для формирования и развития информационного общества, прежде всего, необходимо подготовить кадры, наделенные необходимыми компетенциями. Это обусловлено тем, что инвестиционный характер производства, его высокая наукоемкость, приоритетность вопросов качества продукции должны существенно изменить требования к работнику, повысить значимость трудовых ресурсов [5].

Новая кадровая политика должна основываться на таких положениях, как создание необходимых условий для подготовки компетентных высококвалифицированных кадров способных освоить профессии рынка веб-разработок, а также системы мотивации по освоению необходимых компетенций в различных областях деятельности. Внедрение инновационных адаптивных систем управления предусматривает, прежде всего, обновление методов и подходов к процессу управлению, изменение технологических процессов производства, переход к более рациональному использованию всех видов ресурсов [6].

Как показало изучение, цифровая экономика является достаточно сложной системой, основанной на взаимодействии большого количества факторов. Для исследования сложных систем необходимо особое единство процедур анализа и синтеза. Существуют различные подходы к их сочетанию. Необходимо отметить, что на практике далеко не всегда используются многие приемы и процедуры системного анализа [7].

Интерес к цифровой экономике во всем мире обусловлен многими причинами, и, прежде всего тем, что в современном обществе с каждым годом все более усиливается роль и значение информационных технологий, а также возрастает их влияние на экономические процессы и развитие всех стран мира без исключения, так как в настоящее время уже более $40 \%$ населения планеты имеют доступ во Всемирную сеть.

Кроме того, необходимо отметить, что использование цифровых технологий для реализации товаров и услуг, оказания государственных услуг, образования граждан позволит всему обществу получить так называемые «цифровые дивиденды», под которыми понимается как рост национального благосостояния, материальная прибыль, так и прозрачность государственного управления [8].

Россия, как и другие страны мирового сообщества, огромное внимание уделяет вопросам обеспечения информационной безопасности особенно объектов стратегического назначения. При этом эксперты отмечают, что в цифровой среде в последнее время наблюдается значительный рост преступлений. Такая ситуация требует от государства разработки совершенно новой системы информационной безопасности во всех секторах экономики.

В настоящее время в России успешно развиваются цифровые платформы, основанные на взаимодействии различных информационных систем, позволившие сделать более доступными для населения государственные услуги в электронном формате, за счет использования единой системы идентификации и аутентификации. Однако, необходимо отметить тот факт, что данные платформы еще недостаточно развиты и доступны в полном объеме не во всех регионах страны.

Подобная ситуация объясняется тем, что использование информационно-телекоммуникационных технологий на региональных и муниципальных уровнях управления слабо развита, так как только около 10 \% муниципальных образований отвечают требованиям по уровню цифровизации. Применение информационно-телекоммуникационных технологий должно ускорить развитие и расширить возможности социально-экономической сферы за счет максимального и эффективного использования потенциал данных в цифровой форме, сделав их одним из ключевых факторов производства.

Еще одним важным для экономики страны направлением в области цифровизации является определение места России на глобальном цифровом рынке. К сожалению, в настоящее время Россия занимает только 41 место в рейтинге стран мира по уровню реализации процессов развития цифровой экономики, что еще раз подтверждает актуальность рассматриваемого вопроса.

Подводя итоги, необходимо отметить, что создание интегрированной информационной системы направленно, прежде всего, на стимулирование развития цифровых технологий и их интенсивное использование в различных секторах экономики, в том числе в социально-экономической сфере, системе государственного управления и бизнесе. 


\section{Литература}

1. Юткина О.В. Системный взгляд на обеспечение глобальных направлений экономической безопасности страны // Экономика и предпринимательство. 2014. № 6 (47). С. 189 - 192.

2. Сагынбекова А.C. Цифровая экономика: понятие, перспективы, тенденции развития в России // Международный научно-технический журнал «Теория. Практика. Инновации». 2018. № 4 (28). С. 255 - 275.

3. Александрова М.В., Минаева Е.В. Инновационное развитие как приоритетное направление повышения конкурентоспособности региона // Экономика и предпринимательство. 2018. №8 (97). С. 503 - 507.

4. Аверьянов М.А., Евтушенко С.Н., Кочеткова Е.Ю. Цифровое общество: Новые вызовы // Экономические стратегии. 2016. № 7 (141). С. 90 - 91.

5. Проскурина З.Б. Эффективность использования трудовых ресурсов в условиях рыночной экономики // Экономика, социология и право. 2014. № 7. С. 67 - 70.

6. Минаева E.В., Маслюкова E.A. Современные адаптивные системы управления организациями // Экономика, социология и право. 2014. № 3. С. 60 - 63.

7. Минаева Е.В., Рябова Т.Ф., Деева В.А. Методология исследования сложных систем // Российское предпринимательство. 2008. № 2. С. 86 - 90.

8. Кунгуров Д. Россиян ждет цифровая экономика // Утро.py. 04.12.2016. [Электронный pecypc] URL: https://utro. ru/articles/2016/12/04/1307336.shtml

Ershova Natalia Anatolyevna, Candidate of Economic Sciences, Associate Professor, Head of the Department of Economics, Russian State University of Justice (69, Novocheremushkinskaya Str., Moscow, 117418, Russian Federation). E-mail: nataly_ershova@mail.ru

Alexandrova Margarita Valeryevna, Candidate of Economic Sciences, Associate Professor of the Department of Economics, Russian State University of Justice (69, Novocheremushkinskaya Str., Moscow, 117418, Russian Federation). E-mail: 4664290@mail.ru

\section{PROSPECTS OF INFORMATION SOCIETY DEVELOPMENT IN RUSSIA}

\section{Abstract}

The key objective of the article is to examine the theoretical positions on the birth and development of a new era the era of the digital economy. In the transition to the sixth technological order, digital technologies constantly change the daily life of each subject of economic relations, and also affect production processes, the structure of the country's economy as a whole, education and medicine, cultural and educational sphere, which leads to the need to impose new requirements on information systems.

Keywords: digital economy, information society, technological platforms, information environment, information space, society of knowledge, knowledge of citizens, information infrastructure, competitive productions.

\section{References}

1. YUtkina O.V. Sistemnyj vzglyad na obespechenie global'nyh napravlenij ekonomicheskoj bezopasnosti strany // Ekonomika i predprinimatel'stvo. 2014. № 6 (47). P. 189 - 192.

2. Sagynbekova A.S. Cifrovaya ekonomika: ponyatie, perspektivy, tendencii razvitiya v Rossii // Mezhdunarodnyj nauchno-tekhnicheskij zhurnal «Teoriya. Praktika. Innovacii». 2018. № 4 (28). P. 255 - 275.

3. Aleksandrova M.V., Minaeva E.V. Innovacionnoe razvitie kak prioritetnoe napravlenie povysheniya konkurentosposobnosti regiona // Ekonomika i predprinimatel'stvo. 2018. №8 (97). P. 503 - 507.

4. Aver'yanov M.A., Evtushenko S.N., Kochetkova E.YU. Cifrovoe obshchestvo: Novye vyzovy // Ekonomicheskie strategii. 2016. № 7 (141). C. 90 - 91.

5. Proskurina Z.B. Effektivnost' ispol'zovaniya trudovyh resursov v usloviyah rynochnoj ekonomiki // Ekonomika, sociologiya i pravo. 2014. № 7. P. 67 - 70.

6. Minaeva E.V., Maslyukova E.A. Sovremennye adaptivnye sistemy upravleniya organizaciyami // Ekonomika, sociologiya i pravo. 2014. № 3. P. 60 - 63.

7. Minaeva E.V., Ryabova T.F., Deeva V.A. Metodologiya issledovaniya slozhnyh sistem // Rossijskoe predprinimatel'stvo. 2008. № 2. P. 86 - 90.

8. Kungurov D. Rossiyan zhdet cifrovaya ekonomika // Utro.ru. 04.12.2016. [Elektronnyj resurs] URL: https://utro. ru/articles/2016/12/04/1307336.shtml 